Article

\title{
The Childbirth Fear Questionnaire and the Wijma Delivery Ex- pectancy Questionnaire as Screening Tools for Specific Phobia, Fear of Childbirth
}

\author{
Nichole Fairbrother ${ }^{1 *}$, Arianne Albert ${ }^{3}$, Fanie Collardeau ${ }^{2}$ and Cora Keeney ${ }^{1}$

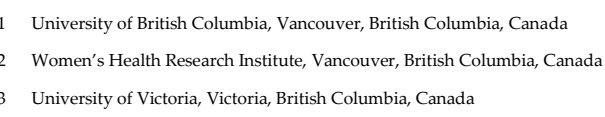

\begin{abstract}
Background: Perinatal anxiety and related disorders are common (20\%), distressing and impairing. Fear of childbirth $(\mathrm{FoB})$ is a common type of perinatal anxiety associated with negative mental health, obstetrical, childbirth and child outcomes. Screening can facilitate treatment access for those most in need. Objectives: The purpose of this research was to evaluate the accuracy of the Childbirth Fear Questionnaire (CFQ) and the Wijma Delivery Expectations Questionnaire (W-DEQ) of FoB as screening tools for specific phobia, FoB. Methods: A total of 659 English-speaking pregnant women living in Canada and over the age of 18 were recruited to the study. Participants completed an online survey of demographic, current pregnancy, and reproductive history information, as well as the CFQ and the W-DEQ, and a telephone interview to assess specific phobia FoB. Results: Symptoms meeting full and subclinical diagnostic criteria for specific phobia, FoB were reported by 3.3\% and $7.1 \%$ of participants, respectively. The W-DEQ met or exceeded the criteria for a "good enough" screening tool across several analyses, whereas the CFQ only met these criteria in one analysis, and came close in three others. Conclusions: The W-DEQ demonstrated high performance as a screening tool for specific phobia, FoB, with accuracy superior to that of the CFQ. Additional research, to ensure the stability of these findings, is needed.
\end{abstract}

Keywords: Perinatal Mental Health; Anxiety Disorders; Perinatal Anxiety; Fear of Childbirth; Screening

\section{Introduction}

Anxiety and anxiety-related conditions are the most prevalent of all psychiatric disorders $[1,2]$. They include the core anxiety disorders (i.e., panic disorder, agoraphobia, specific phobia, social anxiety disorder, and generalized anxiety disorder) as well as obsessive-compulsive disorder (OCD) and posttraumatic stress disorder (PTSD) which, until the publication of the fifth edition of the Diagnostic and Statistical Manual of Mental Disorders (DSM-5) [3] had for 34 years, also been classified as anxiety disorders [4]. The DSM-5 now classifies OCD and PTSD separately in their own sections [3]. There is wide agreement that anxiety is a core feature of these disorders, and they are highly relevant to perinatal people [3]. Consequently, many investigators continue to include them in studies of anxiety [3,4].

A third of the adult population will suffer from one or more anxiety or anxiety-related disorder at some time in their life [1]. This is significantly greater than the prevalence of mood disorders (i.e., depressive and bipolar disorders) at 21.4\% [1]. Women are also 1.5 times as likely as men to suffer from an anxiety or anxiety-related condition [1,2]. A recent meta-analysis indicates that one in five pregnant and postpartum people suffer from one or more anxiety or anxiety-related disorder during pregnancy or the postpartum 
[5]. This is significantly more than perinatal depression, where six to twelve percent of pregnant and postpartum people suffer from an episode of major depression during the perinatal period [6,7].

Anxiety and anxiety-related disorders are associated with substantial indirect costs related to functional impairment (e.g., diminished work capacity, unemployment) [6]. People with these conditions are significantly more impaired with respect to social, emotional and physical functioning compared with non-anxious individuals [8]. The anxiety and their related disorders are associated with high levels of health care service utilization [9-13].

Maternal prenatal anxiety (i.e., dimensional anxiety not necessarily associated with a diagnosis) is associated with numerous adverse pregnancy outcomes such as preterm delivery, miscarriage, preeclampsia, and low birth weight [14-18], as well as prolonged negative effects on the developing infant (e.g., impaired brain activity, difficult temperament, impaired self-regulation and motor development, and an increased risk for attention-deficit/hyperactivity disorder) [15,19-24]. Prenatal maternal anxiety is also a strong risk factor for postpartum depression, even after controlling for prenatal depression [25-28]. The anxiety and their related disorders, specifically, have also been found to be associated with a deleterious fetal, infant and maternal outcome, including pregnancy complications and preterm birth, spontaneous abortions, neonatal morbidity, and lower birth weight [29-33]. For example, mothers with postpartum obsessive-compulsive disorder have been found to be less confident and sensitive in mother-infant interactions than mothers without obsessive-compulsive disorder [34]. As well, maternal postpartum social anxiety disorder has been associated with reduced cognitive and language abilities in offspring [35]. Overall, maternal AD are predictive of anxiety disorders in offspring [36].

There are a number of domains of anxiety (i.e., content areas) that are a particular focus among perinatal people. These include OCD in which the focus of the obsessions (a core feature of OCD) is on harm coming to one's infant, PTSD subsequent to a traumatic childbirth, a fear of needles or other medical procedures (e.g., instrumental or surgical birth), pregnancy-specific anxiety (i.e., high anxiety related to the wellbeing of one's pregnancy), and fear of childbirth (FoB). FoB is the focus of the current study.

FoB is common among people with childbearing potential (i.e., people who are pregnant, may become pregnant or who have already given birth). In the most comprehensive systematic review and meta-analyses of FoB in pregnant women conducted to date, the worldwide pooled prevalence of FoB was estimated at $14 \%$ (95\% CI $0.12-0.16)$ [37]. The study was based on data from 29 primary studies and included a total of 853,988 pregnant women. Prevalence estimates from individual studies varied significantly from 3.7 to $43 \%$. Of concern is that there was a high level of between study heterogeneity, not explained via sensitivity and subgroup analyses. Unexplained variability in prevalence estimates may be a result of the significant methodological variability across studies (e.g., variability in cut-scores and measurement tools). Historically, FoB has not been conceptualized as a diagnosable mental health condition, but rather a form of dimensional psychological distress characterized by fear and anxiety and assessed via self-report inventory [37]. When mental health difficulties are assessed using self-report questionnaires, prevalence estimates tend to be much higher than when formal diagnostic criteria are employed [38-40]. For example, all of the studies included in this meta-analysis of prevalence employed selfreport questionnaires and not diagnostic interviews. The one study in which diagnostic criteria was clearly employed also, as expected, reported a much lower prevalence of FoB (3.7\%) compared with the meta-analysis as a whole [41].

This is problematic because, in the absence of clear diagnostic criteria, it may be difficult to determine what cut-score best represents clinically meaningful fear which may merit treatment. Specifically, to merit the diagnosis of an anxiety disorder, symptoms must be clinically distressing or functionally impairing [3]. Although not yet fully established, it appears that specific phobia may be the most appropriate diagnostic category 
for $\mathrm{FoB}$, in particular for nulliparous people [42-45]. A specific phobia is a fear and avoidance of circumscribed objects and situations (e.g., insects, animals, heights, blood, injections). Given that FoB is a circumscribed fear with symptoms and features closely resembling those of other specific phobias, it has been proposed as perhaps the most appropriate diagnostic classification for FoB [42-45]. In the only study to evaluate this systematically $(\mathrm{N}=106), 8.5 \%$ of study participants (a general sample of nulliparous pregnant women in Sweden) were found to meet DSM-5 diagnostic criteria for specific phobia FoB [42]. Although small $(\mathrm{N}=106)$, this is also the only study published to date to assess any selfreport measure of FoB as a potential screening tool for diagnosable FoB [42]. In this study a W-DEQ score of $\geq 85$ was found to be the optimal cut-off score for identifying FoB, with excellent sensitivity (100\%), specificity (93.8\%), and agreement between the W-DEQ A and the SCID-5 (specific phobia; Cohen's Kappa coefficient, $\kappa=0.720$ ). Determining appropriate cut-scores for self-report measures of FoB can be aided via studies in which diagnostic interviews for specific phobia, FoB are also employed, and screening metrics evaluated. In the absence of this, it is difficult to determine if cut-scores based on other approaches (e.g., the top $25 \%$ of scores) actually represent clinically meaningful distress and/or impairment in functioning.

FoB is often distressing, and associated with various psychosocial, mental health, obstetrical, childbirth, and child related outcomes [46-49]. For some, FoB is so intense as to lead to delaying or avoiding pregnancy, and pregnancy termination, even among those who wish to bear children [50-52]. Obstetrical and birth complications include increased requests for epidural anesthesia during labour [50,52], longer labours [53-55] and a higher likelihood of emergency and planned CS [44,54,56-60]. For example, a study of 6,422 pregnant women from six European countries showed that $16.7 \%$ of nulliparas and $31.7 \%$ of multiparas with severe FoB had a Cesarean section without medical indications (compared to $4.6 \%$ and $17.5 \%$ of women without severe fear of birth; Ryding et al., 2015). In one Finnish study, $8 \%$ of Cesarean sections at one hospital were potentially attributable to fear of vaginal delivery [61]. Elevated fear of vaginal birth is consistently associated with preferences for CS among pregnant women [60,62], and women who plan to become pregnant [63]. There is also a higher likelihood of negative birth experiences among women with a fear of childbirth $[64,65]$, especially if the woman delivered by emergency CS or instrumental vaginal delivery [53,66]. There is also an association between FoB and mental health difficulties including postnatal depression, specific phobia, and posttraumatic stress disorder (PTSD) [67-70].

In particular, there is a strong association between previous negative birth experiences and/or traumatic births, and FoB [69]. Studies have also shown that the odds of FoB increase with the number of obstetric complications experienced during a previous pregnancy [66]. Women with a previous negative birth experience are 5 times more likely to experience FoB in a subsequent pregnancy [66]. History of prior operative or instrumental delivery has also been associated with higher levels of $\mathrm{FoB}[58,59,71]$. Although most studies have found a positive relationship between parity and FoB, with higher levels of childbirth fear reported by nulliparous compared with multiparous women $[47,49,52,59,71-74]$ there is some evidence that the most severe levels of FoB are experienced by multiparous women [41].

A range of socio-demographic variables are associated with higher levels of childbirth fear including lower educational attainment, younger age $[75,76]$, low social support $[61,76]$, and dissatisfaction with partner or support received from partner [61,75], mental health variables such as higher anxiety and stress [44,58,61,73,75,77], history of depression and depression during pregnancy $[62,75,78,79]$, low confidence in one's ability to cope with labour and birth $[62,75,78,79]$, and history of abuse $[47,77,80]$. In terms of physical health, higher levels of fatigue during pregnancy [81] and lower self-rated health (Qiu et al., 2020) have also been associated with higher levels of FoB. 
Our study team recently developed a new measure of FoB: The Childbirth Fear Questionnaire (CFQ) [82]. The CFQ was designed to overcome limitations of existing measures, and as a screening tool for FoB. Existing measure frequently omit important domains of FoB [57,71,76,83-91], include non-fear related items [83,85,87,89-92], are too brief to encompass the full FoB experience (e.g., 1-2 items only) $[57,71,76,86]$, or include too few items per subscale to achieve stability $[87,93]$. We developed the CFQ to cover the full range of domains of $\mathrm{FoB}$, with a view to enabling an identification of specific fear domains to be targeted in treatment. We also sought to develop a measure that would function well as a screening tool for diagnosable FoB. Screening represents a critical step in the pathway to treatment [94]. Although diagnostic assessments by trained professionals are the gold standard for providing mental health diagnoses, they are both expensive and time-consuming. Consequently, more rapid, and cost-effective screening is essential for identifying those suffering from clinically meaningful FoB. Without screening, those suffering may fail to be identified and as a result, fail to receive evidence-based care [95]. The CFQ has been evaluated in two separate samples, with both an exploratory and a confirmatory factor analysis. Psychometric properties of the CFQ are strong, and two manuscripts pertaining to this measure have been published with a third currently under review $[72,82,96]$.

The primary objective of this research was to evaluate the screening accuracy of the CFQ for specific phobia, FoB. A secondary objective was to compare the screening accuracy of the CFQ to the screening accuracy of the W-DEQ. Given known differences in FoB between nulliparous and multiparous people $[41,72,73]$, we also elected to report screening accuracy of the CFQ and the W-DEQ separately for nulliparous and multiparous participants. As a further distinction, we also report the accuracy of the CFQ and the W-DEQ separately for those primarily fearful of a vaginal birth and those primarily fearful of a cesarean birth. We hypothesized measures of FoB might perform differently for people whose primary fears relate to vaginal delivery compared to those whose primary fears relate to medical and surgical interventions (i.e., cesarean birth) [96]. We chose the WDEQ as the comparator measure because: (a) the W-DEQ is the most commonly used measure to assess FoB and has broad international acceptance [48], (b) the W-DEQ is the only measure of FoB to be evaluated as a screening tool for specific phobia, FoB [48], and (c) the CFQ was developed with a view of overcoming some of the limitations of the WDEQ (i.e., inclusion of non-fear-related items, and a failure to assess all of the relevant FoB content domains) [82]. In contrast with the W-DEQ, the CFQ assesses a broader range of FoB content areas, includes only fear-related items, and includes a measure of interference making it more similar to a diagnostic measure (i.e., mental health diagnoses require either distress or interference in order for a diagnosis to be given).

For all of the above evaluations of screening accuracy, we also sought to evaluate the screening accuracy of the CFQ and the W-DEQ against the criteria for a "good enough" screening tool proposed by Fairbrother and colleagues [97]. They propose that, in order for a screening tool to deemed sufficiently accurate for use in clinical settings, it should meet certain minimum standards of accuracy including an area under the curve (AUC) of .8 or greater, a Youden's $\mathrm{J}$ index of .5 or more $(\mathrm{J}=.05$ when sensitivity and specificity both equal .75), a negative predictive value (NPV) of .8 or greater, and a positive likelihood ratio (LR+) of 4.0 or more. A LR+ of 4.0 means that with a positive test result, one is $25 \%$ more likely to have the condition in question, compared with the baseline probability of having the condition [98]. Any recommendations regarding the accuracy and clinical utility of the CFQ and the W-DEQ will be based on how well they perform in relation to these criteria.

\section{Materials and Methods}

This paper reports on a secondary analysis of a larger dataset, for which detailed methods have been published [82]. 


\subsection{Ethics}

This research received ethical approval from the Behavioral Research Ethics Board of the University of British Columbia. All participants provided informed, written consent prior to participation.

\subsection{Participants}

All English-speaking, pregnant individuals over the age of 18 and residing in Canada were eligible to take part in this study. In total, 881 participants took part in the online questionnaire between 11- and 46-weeks' gestation (average 35-weeks). Primary data collection took place between August 2016 and November 2019.

\subsection{Procedures}

Perinatal people were directed to the online survey via the study advertisement posted on online forums and social media pages frequented by pregnant women (e.g., pregnancy-related Facebook groups and websites). Participants who completed the survey were entered into a draw with the chance to win one of seven $\$ 150$ prizes.

\subsection{Measures}

Demographic (e.g., age, education, marital status, income, race/ethnicity, and country of residence), pregnancy (e.g., number of fetuses, and method of conception), and reproductive history (e.g., the number of prior pregnancies, births, miscarriages, and vaginal and cesarian deliveries) was collected via self-report. Participants were also asked about their delivery preferences, using a 7-point Likert-type scale ranging from very strong desire for a vaginal birth ( 0 ) to very strong desire for a cesarian birth (7).

The Childbirth Fear Questionnaire (CFQ)[82] is a recently developed self-report measure used to assess fear of childbirth. The questionnaire contains 47 items, scored on a Likert-type scale ranging from 0 (no fear) to 4 (extreme fear), and measuring nine, frequently reported dimensions of $\mathrm{FoB}$ and an 8-item interference scale with items covering multiple life domains. Fear dimensions include: (1) fear of loss of sexual pleasure or attractiveness; (2) fear of pain from a vaginal birth; (3) fear of medical intervention; (4) fear of embarrassment; (5) fear of harm to baby; (6) fear of caesarean birth; (7) fear of mom or baby dying; (8) fear of insufficient pain medication; (9) fear of body damage from a vaginal birth. Initial validation of the CFQ produced a Cronbach's alpha reliability coefficient of 0.94 for the overall scale and a range between 0.76 to 0.94 for the individual subscales [72]. The CFQ demonstrated good convergent and discriminant validity, when comparing the associations between the CFQ with other measures of FoB. Evidence suggests that the $\mathrm{CFQ}$ is accurate in detecting group differences between pregnant people in relation to delivery mode preference and parity.

The Wijma Delivery Expectancy Questionnaire (W-DEQ-A)[90]. The W-DEQ-A is a 33-item questionnaire. Items are scored on a 0-5 Likert type scale ranging from 0 (extremely) to 5 (not at all). The minimum and maximum scores of the questionnaires are 0 and 165, with higher scores reflecting higher levels of fear. The psychometric properties of the W-DEQ-A are well established [90,99]. The internal consistency reliability in the present sample was 0.92. As well as the the W-DEQ-A total score, there is data to support the administration of a 6-item fear scale, which was found to be highly correlated with the full scale and several other important outcomes [100].

The Diagnostic Assessment Research Tool (DART v1.03.16) [101]. The DART (v1.03.16) is a modular, semi-structured interview designed for the assessment of DSM-5 diagnoses. Although the DART remains early in its development psychometric evidence to date strongly supports the interrater reliability and construct (convergent and discriminant) validity of the measure as a diagnostic interview for DSM-5 disorders [102]. We used the specific phobia section of the DART to assess specific phobia, fear of childbirth in this 
study. Minor wording modifications were made to orient the interview exclusively to fear of childbirth. Interviewers were research assistants, graduate students in clinical psychology and the principal investigator, and were trained and supervised by the principal investigator. Participants' responses were classified as indicating no diagnosis, a subclinical diagnosis, or a full criteria diagnosis of specific phobia, FoB.

\subsection{Data Analysis Strategy}

All analyses were carried out in R v.4.1.1 [103] and SPSS v.24 [104].

The precision of estimates of a diagnostic accuracy study depends on the prevalence of the condition in the sample [105]. The lower the prevalence, the larger the number of participants with cases needed to precisely estimate metrics such as sensitivity and specificity, as lower prevalence results in estimated metrics that can be unreliable and imprecise [106]. For these reasons, we conducted an assessment of screening accuracy for both subclinical and full criteria diagnoses of specific phobia, FoB. Specifically, we began by comparing cases with a diagnosis meeting full criteria for specific phobia, FoB to the remainder of the sample (Table 3). However, due to small numbers of cases meeting full criteria, we also compared cases of full and subclinical criteria to the remainder of the sample (see Tables 4 and 5 of the Results).

Given the data indicating that childbirth fears may differ among nulliparous and multiparous people [73], we felt it was important to provide information about screening accuracy for each group separately. We have also provided screening accuracy data for the CFQ (total scores) with and without the Interference subscale included. We sought to investigate whether the interference subscale would improve screening accuracy.

To determine optimal cutpoints we used the 'cutpointr' [107] package in R. Cutpoints were estimated by maximizing the Youden's J index using 1000 bootstrap replicates. The returned optimal cutpoint, and its associated AUC, sensitivity, specificity, J index, NPV and (LR+) were the means of these metrics across all 1000 replicates. This whole process was itself bootstrapped 100 times to validate the out of sample performance. These 'out of bag' or oob estimates are reported in the Results.

\section{Results}

\subsection{Participants}

A total of 659 pregnant people participated in this study. Participants ranged in age from 21 to $49(\mathrm{M}=32.9, \mathrm{SD}=4.10)$. Of these, $270(48 \%)$ were nulliparous at the time of participation, and 296 (52\%) were multiparous. Information pertaining to participant demographics, current pregnancy and reproductive history is provided in Table 1 . Means and standard deviations for the CFQ and the W-DEQ are reported in Table 2.

Table 1. Participant demographic information and reproductive information $(\mathrm{N}=659)$.

\begin{tabular}{ccc}
\hline & Demographic variables & \\
\hline & Percentage & n \\
\hline Married or cohabitating & $93.3 \%$ & 613 \\
Cis-gender female & $99.1 \%$ & 652 \\
Some postsecondary education & $94.4 \%$ & 623 \\
European heritage & $76.3 \%$ & 502 \\
English spoken at home & $95.4 \%$ & 629 \\
\hline & Current pregnancy & \\
\hline Singleton pregnancy & $97.7 \%$ & 642 \\
Weeks pregnant: M (SD) & $34.6(2.1)$ & 497 \\
Pregnancy complications & $30.8 \%$ & 202 \\
\hline Reproductive history & & \\
\hline Prior births & $52.3 \%$ & 198
\end{tabular}




\begin{tabular}{ccc} 
Prior cesarean birth & $17.7 \%$ & 66 \\
Prior pregnancy loss $<20$ weeks & $40.6 \%$ & 157 \\
Prior pregnancy loss $>20$ weeks & $1.3 \%$ & 5 \\
\hline
\end{tabular}

Table 2. Means and standard deviations for CFQ (total and subscales) and the W-DEQ.

\begin{tabular}{cccc}
\hline & Full Sample & Nullips Only & Multips Only \\
& M (SD) & M (SD) & M (SD) \\
\hline CFQ Total & $1.11(.59)$ & $1.23(.61)$ & $1.02(.56)$ \\
CFQ Interference & $.42(.47)$ & $.44(.47)$ & $.39(.45)$ \\
W-DEQ & $55.44(23.76)$ & $59.07(22.77)$ & $52.8(24.09)$ \\
\hline
\end{tabular}

Note: $C F Q$ Total and CFQ Interference scores are mean items scores (i.e., out of a possible 0-4). W-DEQ scores are for the total out of 33 items.

\subsection{Prevalence of specific phobia, fear of childbirth}

Twenty-two (3.3\%) participants reported symptoms meeting full diagnostic criteria for specific phobia, fear of childbirth, and 47 (7.1\%) reported symptoms meeting subclinical criteria for specific phobia, fear of childbirth. When segregated by parity, fewer $(1.9 \%)$ nulliparous participants met full criteria for specific phobia compared with multiparous participants (5.1\%). However, similar proportions of nulliparous and multiparous participants met subclinical criteria for specific phobia, fear of childbirth (6.3 and 6.8\%, respectively).

\subsection{ROC curves and diagnostic accuracy}

We present the screening metrics for the CFQ and the W-DEQ in Tables 3 through 5, with corresponding ROC curves presented in Figures 1 through 3. In Table 3, screening metrics are provided for the CFQ (both with and without the Interference Subscale) and the W-DEQ for specific phobia, FoB, full criteria across parity groups. In Table 4, we present the same findings, but for specific phobia FoB, full criteria and subclinical combined. In Table 5, we present the screening metrics for the CFQ (including the Interference Subscale) and the W-DEQ across parity groups, separately for those primarily fearful of a vaginal birth and those primarily fearful of a cesarean birth. For this table, there were not enough cases to present the screening accuracy of the W-DEQ for fear of cesarean birth. Consequently, only the W-DEQ screening accuracy for fear of vaginal birth is provided. Given the smaller samples available for this final analysis, screening metrics are provided for subclinical and full diagnostic criteria cases combined.

The W-DEQ evidenced the highest level of screening accuracy, meeting or exceeding the criteria for a "good enough" screening tool across several analyses. Specifically, when comparing those reporting symptoms meeting full diagnostic criteria for specific phobia, FoB compared to the remainder of the sample, the W-DEQ met or exceeded the "good enough" criteria for both nulliparous and multiparous participants, and came close to meeting these criteria for the full sample. When comparing those who reported symptoms meeting full or subclinical diagnoses with the remainder of the sample, the W-DEQ exceeded the criteria for a "good enough" screening tool for multiparous participants (in general and among those primarily fearful of a vaginal birth), as well as for all participants primarily fearful for a vaginal birth.

The CFQ only met or exceeded the criteria for a "good enough" screening tool for nulliparous participants primarily fearful of a vaginal birth. When comparing those reporting symptoms meeting full or subclinical diagnoses with the remainder of the sample, the CFQ came close to meeting the criteria for a "good enough" screening tool for nulliparous participants in general, for nulliparous participants primarily fearful of a cesarean birth, and for those primarily fearful of a vaginal birth (full sample). 
Table 3. ROC results for the CFQ and the W-DEQ across parity (full diagnostic criteria ONLY).

\begin{tabular}{|c|c|c|c|c|c|c|c|c|c|}
\hline & & Prevalence & AUC & $J$ & Cutpoint & Sensitivity & Specificity & NPV & LR+ \\
\hline \multirow{3}{*}{$\begin{array}{c}\text { CFQ Total } \\
\text { Scores }\end{array}$} & Full sample & $3.3 \%$ & .63 & .11 & 1.17 & .56 & .55 & .97 & 1.24 \\
\hline & $\begin{array}{l}\text { Nulliparous } \\
\text { only }\end{array}$ & $1.9 \%$ & .45 & .45 & 1.34 & .60 & .45 & .98 & 1.09 \\
\hline & $\begin{array}{c}\text { Multiparous } \\
\text { only }\end{array}$ & $5.0 \%$ & .67 & .17 & 1.05 & .60 & .57 & .96 & 1.40 \\
\hline \multirow{3}{*}{$\begin{array}{c}\text { CFQ Total } \\
\& \\
\text { Interference } \\
\text { Subscale } \\
\text { Scores }\end{array}$} & Full sample & $3.3 \%$ & .62 & .10 & 1.13 & .53 & .57 & .97 & 1.23 \\
\hline & $\begin{array}{c}\text { Nulliparous } \\
\text { only }\end{array}$ & $1.9 \%$ & .56 & .23 & .69 & 1.00 & .23 & 1.0 & 1.30 \\
\hline & $\begin{array}{c}\text { Multiparous } \\
\text { only }\end{array}$ & $5.0 \%$ & .69 & .35 & 1.63 & .47 & .89 & 97 & 4.27 \\
\hline \multirow{3}{*}{ W-DEQ } & Full sample & $3.9 \%$ & .82 & .43 & 78.87 & .62 & .81 & .98 & 3.26 \\
\hline & $\begin{array}{c}\text { Nulliparous } \\
\text { only }\end{array}$ & $2.5 \%$ & .88 & .69 & 95.37 & .75 & .94 & .99 & 12.50 \\
\hline & $\begin{array}{c}\text { Multiparous } \\
\text { only }\end{array}$ & $5.9 \%$ & .83 & .53 & 76.56 & .70 & .83 & .98 & 4.12 \\
\hline
\end{tabular}

Note: Cut scores for the CFQ are mean items scores (i.e., out of a possible 0-4). W-DEQ cut scores are for the total out of 33 items.

Table 4. ROC Results for the CFQ and the W-DEQ across parity (subclinical and full diagnostic criteria combined).

\begin{tabular}{|c|c|c|c|c|c|c|c|c|c|}
\hline & & Prevalence & AUC & $J$ & Cutpoint & Sensitivity & Specificity & NPV & LR+ \\
\hline \multirow{3}{*}{$\begin{array}{c}\text { CFQ Total } \\
\text { Scores }\end{array}$} & Full sample & $10.0 \%$ & .72 & .29 & 1.18 & .29 & .69 & .90 & .94 \\
\hline & $\begin{array}{l}\text { Nulliparous } \\
\text { only }\end{array}$ & $8.0 \%$ & .75 & .30 & 1.46 & .66 & .64 & 96 & 1.83 \\
\hline & $\begin{array}{c}\text { Multiparous } \\
\text { only }\end{array}$ & $12.0 \%$ & .71 & .26 & 1.13 & .63 & .63 & .93 & 1.70 \\
\hline \multirow{3}{*}{$\begin{array}{c}\text { CFQ Total } \\
\& \\
\text { Interference } \\
\text { Subscale } \\
\text { Scores } \\
\end{array}$} & Full sample & $10.0 \%$ & .73 & .30 & 1.13 & .69 & .61 & .95 & 1.77 \\
\hline & $\begin{array}{l}\text { Nulliparous } \\
\text { only }\end{array}$ & $8.0 \%$ & .77 & .37 & 1.38 & .71 & .66 & .96 & 2.09 \\
\hline & $\begin{array}{c}\text { Multiparous } \\
\text { only }\end{array}$ & $12.0 \%$ & .73 & .30 & 1.05 & .67 & .63 & .93 & 1.81 \\
\hline \multirow{3}{*}{$\begin{array}{c}\text { W-DEQ } \\
\text { Total Scores }\end{array}$} & Full sample & $9.0 \%$ & .79 & .47 & 73.59 & .68 & .79 & .96 & 3.24 \\
\hline & $\begin{array}{l}\text { Nulliparous } \\
\text { only }\end{array}$ & $7.0 \%$ & .68 & .26 & 81.51 & .44 & .82 & .95 & 2.44 \\
\hline & $\begin{array}{c}\begin{array}{c}\text { Multiparous } \\
\text { only }\end{array} \\
\end{array}$ & $11.0 \%$ & .88 & .53 & 70.62 & .74 & .79 & .96 & 3.52 \\
\hline
\end{tabular}

Note: Cut scores for the CFQ are mean items scores (i.e., out of a possible 0-4). W-DEQ cut scores are for the total out of 33 items.

Table 5. ROC Results for the CFQ (Total and Interference Subscale scores) and the W-DEQ, separately for fear of vaginal and fear of cesarean birth (subclinical and full diagnostic criteria combined).

\begin{tabular}{cccccccccc}
\hline \multicolumn{10}{c}{ CFQ Total \& Interference Subscale scores } \\
\hline & & Prevalence & AUC & $\boldsymbol{J}$ & Cutpoint & Sensitivity & Specificity & NPV & LR+ \\
\hline \multirow{2}{*}{ Fear of Vaginal } & Full sample & $3.2 \%$ & .81 & .43 & 1.38 & .71 & .72 & .99 & 2.54 \\
Birth & Nulliparous only & $\mathbf{1 . 5 \%}$ & $\mathbf{. 8 8}$ & $\mathbf{. 6 7}$ & $\mathbf{1 . 4 2}$ & $\mathbf{1 . 0 0}$ & $\mathbf{. 6 7}$ & $\mathbf{1 . 0 0}$ & $\mathbf{3 . 0 3}$ \\
& Multiparous only & $4.1 \%$ & .80 & .44 & 1.38 & .67 & .77 & .98 & 2.91 \\
\hline \multirow{2}{*}{ Fear of } & Full sample & $6.9 \%$ & .71 & .27 & 1.04 & .73 & .54 & .96 & 1.59 \\
cesarean birth & Nulliparous only & $4.9 \%$ & .78 & .49 & 1.51 & .77 & .72 & .98 & 2.75 \\
& Multiparous only & $8.6 \%$ & .73 & .39 & .94 & .84 & .55 & .97 & 1.87 \\
\hline \multirow{2}{*}{ Fear of Vaginal } & & Prevalence & AUC & $J$ & Cutpoint & Sensitivity & Specificity & NPV & LR+ \\
\hline Birth & Full sample & $\mathbf{4 . 2 \%}$ & $\mathbf{. 8 6}$ & $\mathbf{. 5 6}$ & $\mathbf{7 8 . 8 7}$ &. $\mathbf{7 4}$ & $\mathbf{8 3}$ & $\mathbf{. 9 9}$ & $\mathbf{4 . 3 5}$ \\
& Nulliparous only & $2.5 \%$ & .73 & .70 & 96.36 & .75 & .95 & .99 & 15.0 \\
& Multiparous only & $\mathbf{5 . 3 \%}$ & $\mathbf{. 9 2}$ & $\mathbf{. 7 0}$ & $\mathbf{7 5 . 2 4}$ & $\mathbf{. 8 9}$ & $\mathbf{. 8 1}$ & $\mathbf{. 9 9}$ & $\mathbf{4 . 6 8}$ \\
\hline
\end{tabular}


A Full sample

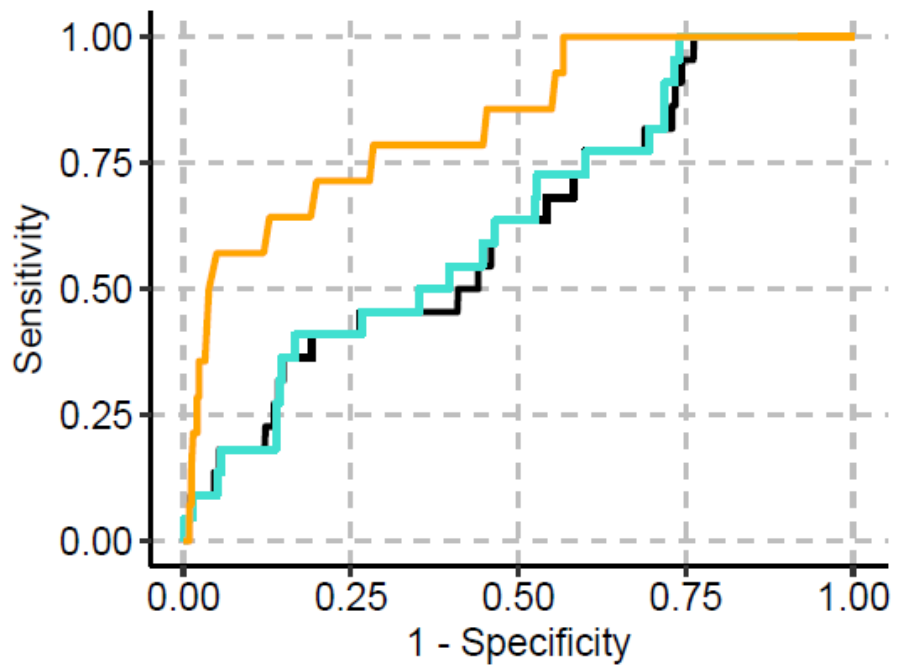

C Multiparous sample

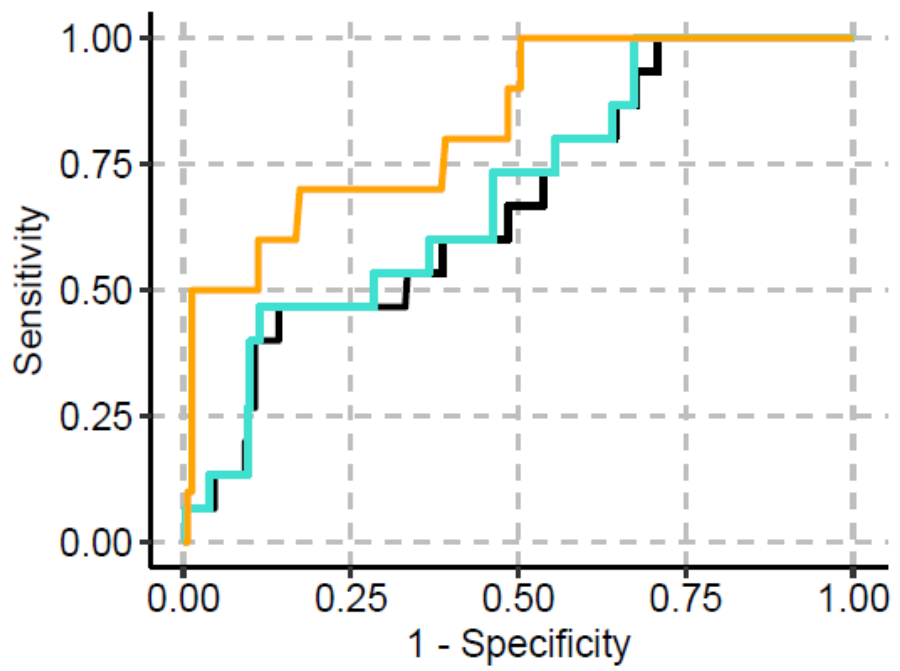

B Nulliparous sample

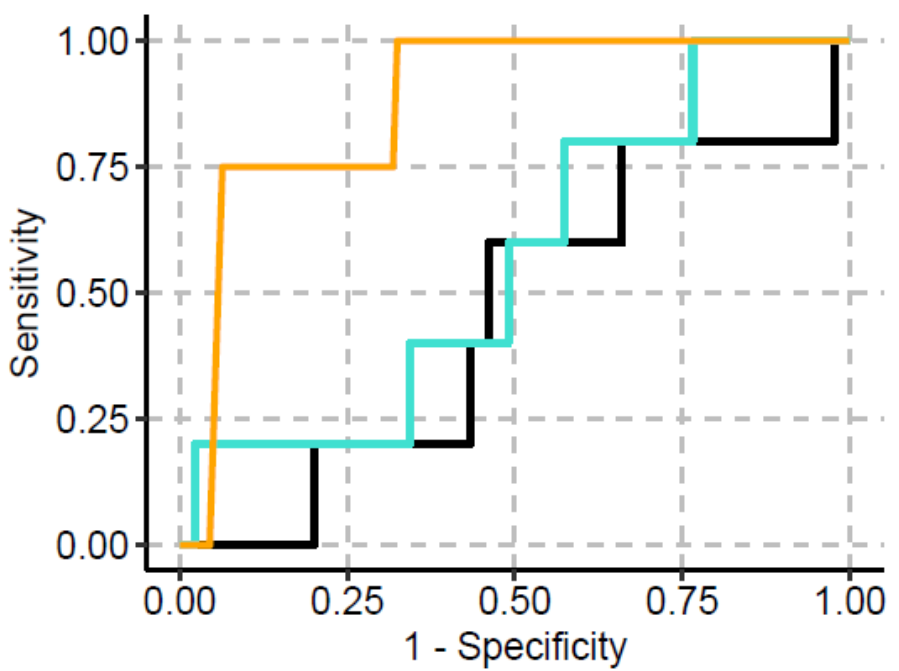

CFQ-TOT CFQ-TOT \& Interference W WEQ

Figure 1. ROC curves for the CFQ and the W-DEQ across parity (full diagnostic criteria ONLY). 


\section{A Full sample}

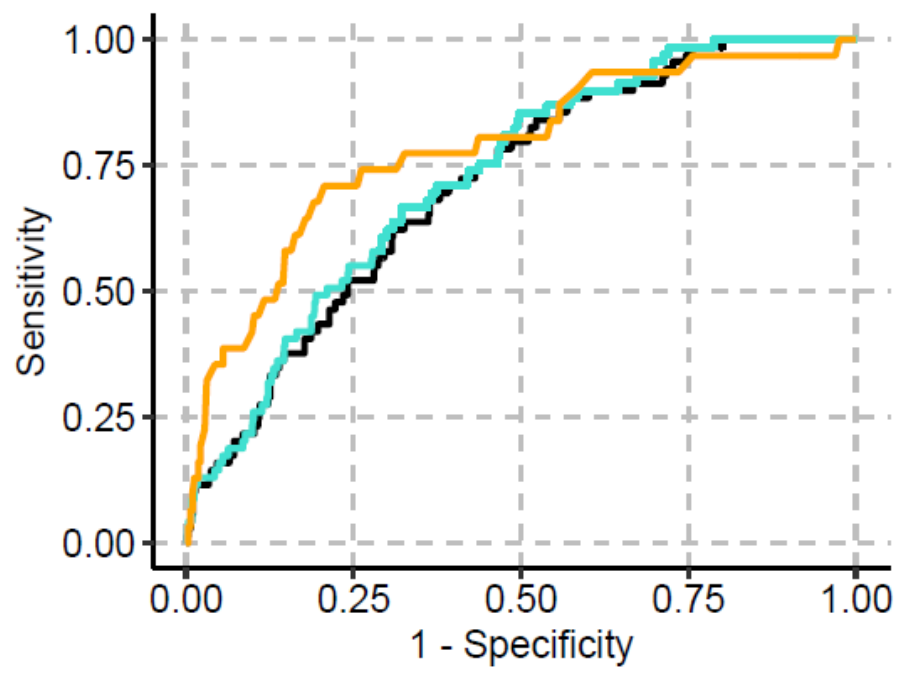

C Multiparous sample

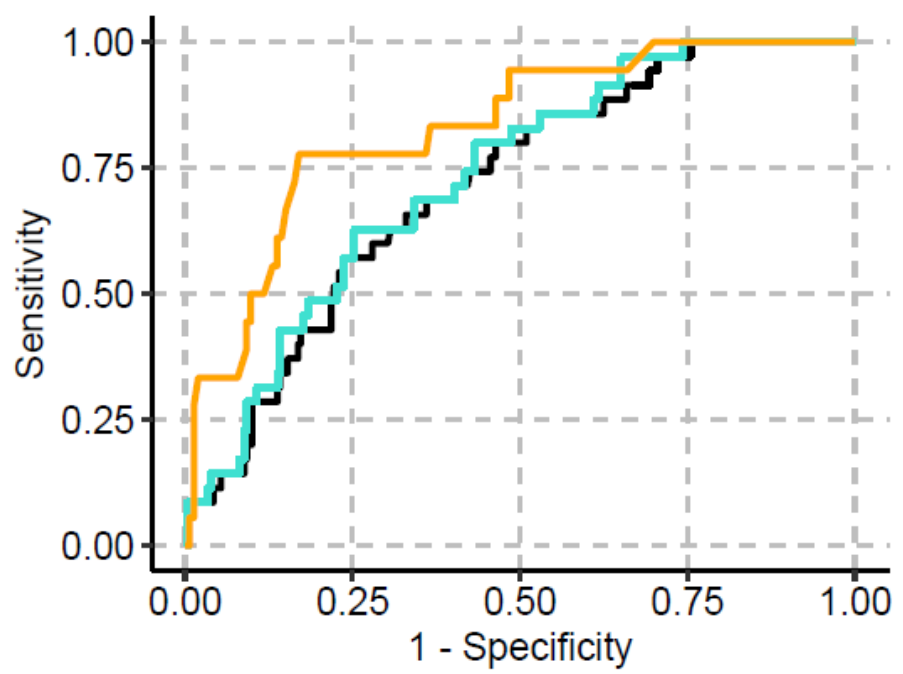

- CFQ-TOT $=$ CFQ-TOT \& Interference - WDEQ

Figure 2. ROC curves for the CFQ and the W-DEQ across parity (subclinical and full diagnostic criteria combined).
B Nulliparous sample

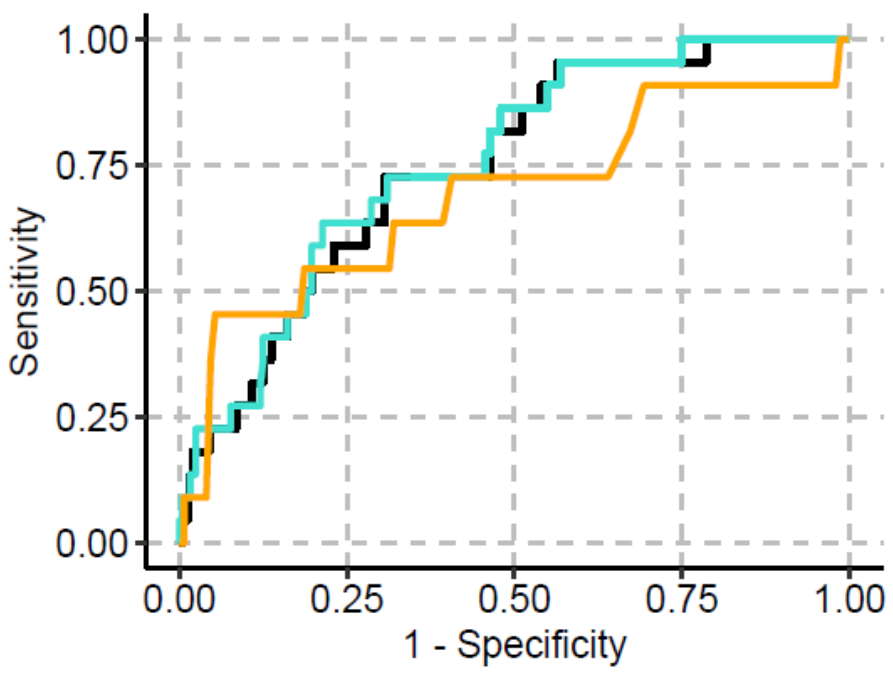


A Fear of vaginal birth - CFQ

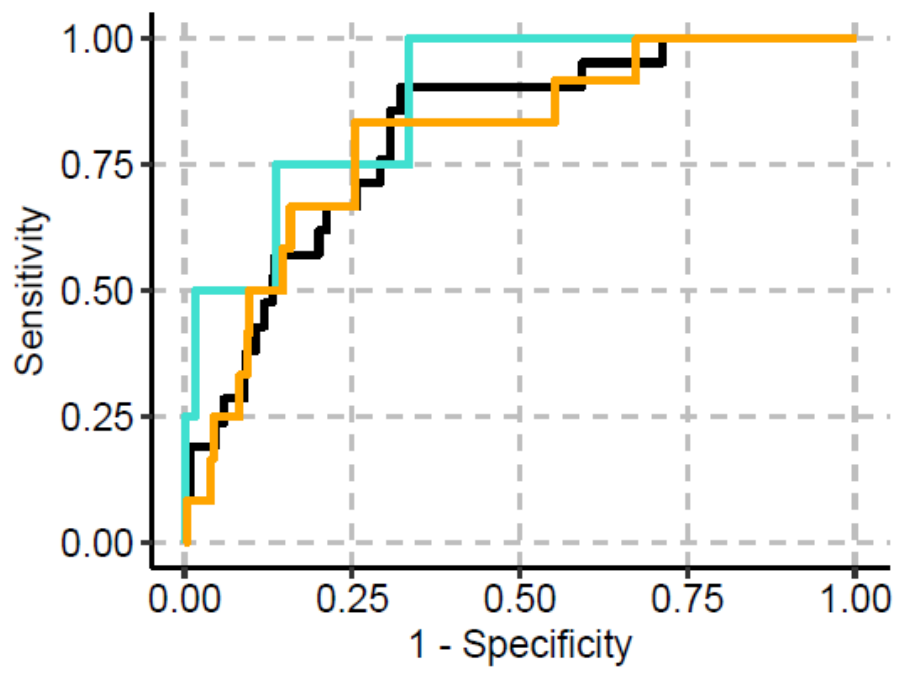

\section{Fear of vaginal birth - WDEQ}

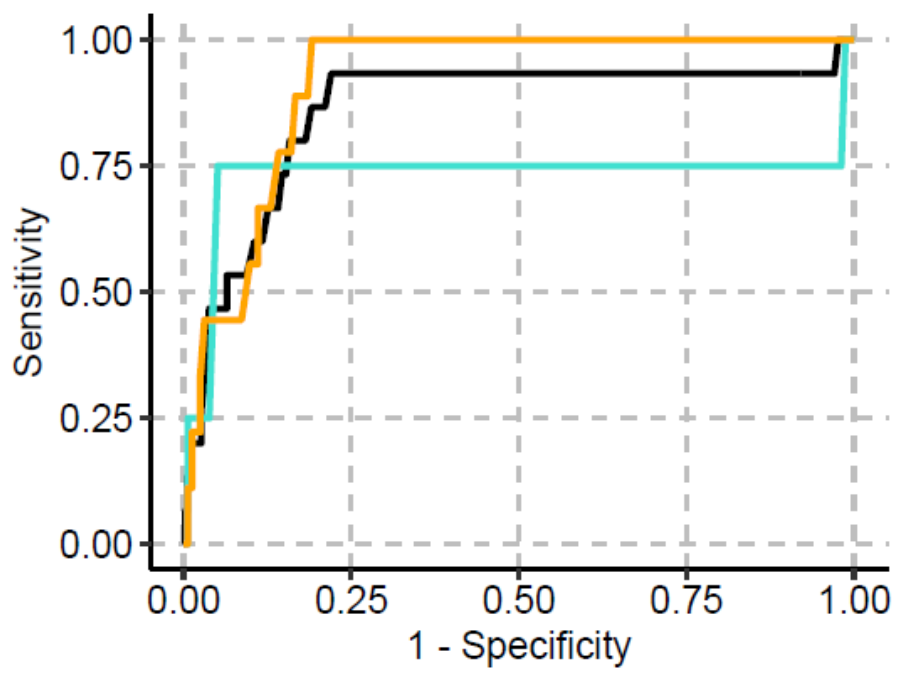

B Fear of cesarean birth - CFQ

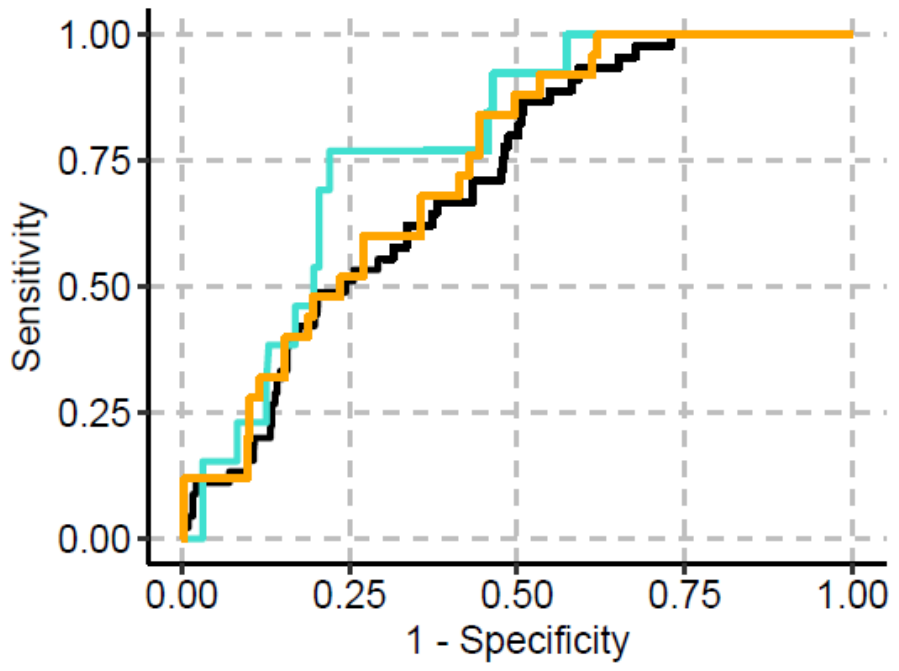

Full sample Nulliparous $=$ Multiparous

Figure 3. ROC curves for the CFQ (Total and Interference Subscale scores) and the W-DEQ, separately for fear of vaginal and fear of cesarean birth (subclinical and full diagnostic criteria combined).

\section{Discussion}

In the current study, strong support was found for the W-DEQ as a screening tool for specific phobia, FoB. Specifically, the W-DEQ either met or exceeded the criteria for a "good enough" screening tool across multiple comparisons. These findings are consistent with, and build upon, findings from the only other study of the W-DEQ as a screening tool for specific phobia, FoB [42]. In that previous small $(\mathrm{N}=106)$ study of the screening accuracy of the W-DEQ for specific phobia, FoB, among nulliparous pregnant people, the W-DEQ evidenced an AUC of .96, and a Youden's index of .93. The optimal cut score was determined to be 85 . The authors compared participants reporting symptoms meeting full criteria for specific phobia, FoB to those who did not. In the present study, the same analysis (i.e., full diagnostic criteria for nulliparous participants only) produced an AUC of .88 , a Youden's index of .69, and an optimal cut score of 95.4. Together, these two studies support the screening accuracy of the W-DEQ for specific phobia, FoB. A note of caution 
regarding these findings is merited given the small numbers of positive cases in both studies, in particular the smaller study by Calderani and colleagues [42].

In contrast with our expectations, the CFQ performed less well than the W-DEQ as a screening tool for specific phobia, FoB. We had anticipated that the CFQ, by virtue of its emphasis on fear, and its multidimensional assessment of FoB, would outperform the WDEQ, but this was not the case. Furthermore, the CFQ only met the criteria for a "good enough" screening tool (excluding the positive likelihood ratio) for nulliparous participants primarily fearful of a vaginal birth. The CFQ came close to meeting these criteria in three other comparisons: for nulliparous participants in general, for those primarily fearful of a cesarean birth, and for those primarily fearful of a vaginal birth (nulliparas and multiparas together). Differently from the CFQ, the W-DEQ includes items assessing other, non-fear-related cognitive and emotional responses to childbirth (e.g., fantastic, lonely, strong, weak, desolate) with only a small number of items specifically assessing fear. On the other hand, the CFQ attempts to encompass the range of perinatal people's childbirth related fears by assessing multiple domains of FOB. It may be that items assessing broad cognitive and emotional responses to childbirth, similarly to the W-DEQ, provide an easier and more accurate measure of pregnant people's immediate emotional reaction to thinking about childbirth.

The W-DEQ appears to perform best when comparing pregnant people who have reported symptoms meeting full diagnostic criteria for FoB compared to those who did not report symptoms meeting these criteria, whereas the CFQ performed best when comparing participants reporting symptoms meeting full or subclinical criteria for specific phobia FoB to the remainder of the sample. A note of caution here is also merited due to the fact that the number of participants meeting full criteria was small rendering estimates of performance unstable. Additional research involving larger samples is needed to fully clarify the merits and disadvantages of screening for specific phobia, FoB full criteria versus full or subclinical, and to ensure the stability and replicability of estimates of performance, especially for comparisons of specific phobia, FoB full diagnostic criteria to all other participants.

Interestingly, when we compared participants who reported symptoms meeting full or subclinical diagnostic criteria for specific phobia, FoB to the remainder of the sample, the W-DEQ performed best when limiting these analyses to participants who were primarily fearful of a vaginal birth. It may be that the $\mathrm{W}$-DEQ performs best for people who are most fearful of vaginal birth, but additional research will be needed to clarify this. Of note, when limiting the analysis to those primarily fearful of a vaginal birth, the W-DEQ performed best for multiparous participants. This is counter-intuitive in that one might expect the fears of multiparous people to more closely resemble symptoms of posttraumatic stress disorder, and not specific phobia $[50,68]$.

When both subclinical and full criteria diagnoses were considered together, the screening accuracy of the CFQ was highest for nulliparous participants. This was true overall, but also when assessing screening accuracy separately for participants primarily fearful of vaginal birth and those primarily fearful of cesarean birth. This same pattern did not hold when only those reporting symptoms meeting full criteria for specific phobia, FoB were compared to the remainder of the sample. Again, additional research is needed to better understand the implications of comparing pregnant people who report symptoms meeting full diagnostic criteria for specific phobia, FoB to the remainder of the sample, versus when comparisons involve grouping together those who report symptoms meeting full and subclinical diagnostic criteria.

What was clear in this study is that the inclusion of the Interference subscale of the CFQ improved the measure's screening accuracy. This pattern was consistent across evaluations of the CFQ when comparing participants who reported symptoms meeting full diagnostic criteria against all other participants, as well as when comparisons were made with participants reporting symptoms meeting full or subclinical diagnostic criteria 
against all other participants. Any clinical applications of the CFQ as a screening tool for specific phobia, FoB should include this component of the measure.

\section{Limitations and future directions}

Although this study was adequately powered $(\mathrm{N}=659)$, subsamples of participants reporting symptoms meeting full diagnostic criteria for specific phobia, FoB were much smaller. Consequently, we were unable to conduct all ROC analyses comparing participants whose symptoms met full criteria for specific phobia, FoB against the remaining participants. Some ROC analyses we compared those who reported symptoms meeting full or subclinical criteria against the remaining participants. This improved power but may not fully generalize to pregnant people with symptoms meeting full criteria for specific phobia FoB. Future research with larger samples will be able to refine some of the findings from the present research.

Given that specific phobia may not be the only diagnostic category most relevant for FoB, it would be extremely helpful to evaluate the ability of the CFQ and the W-DEQ to screen for any mental health diagnosis under which a particular person's FoB may fall. For example, for some people, FoB may be best characterized as posttraumatic stress disorder, whereas for others it may be best understood as specific phobia or health anxiety. It would be helpful to know if the majority of people whose FoB is severe enough to merit a mental health diagnosis can be captured by the CFQ or the W-DEQ. Studies in which the screening ability of these two measures are assessed against a broader range of anxiety-related conditions will be able to answer this question.

Future research may benefit from regression analyses of the CFQ subscales to ascertain if there may be scoring algorithms which increase the screening accuracy of the CFQ for particular subgroups (i.e., nulliparas versus multiparas, and those primarily fearful of one specific mode of delivery). It may be the that the screening accuracy of the CFQ can be enhanced via this approach. Future research will also be needed to ascertain the utility of the CFQ and W-DEQ in diverse cultural groups, social contexts (e.g., lower socio-economic status) and countries.

\section{Conclusions}

The W-DEQ performs well as a screening tool for specific phobia, FoB, for pregnant people overall and across various subgroups (e.g., nulliparous and multiparous pregnant people). The CFQ performs less well as a screening tool for specific phobia, FoB, but nevertheless holds promise. Additional research is needed to ensure replicability of findings, and to further evaluate the potential of the CFQ to accurately screen for diagnosable FoB.

Author Contributions: NF developed the manuscript concept and was responsible for the study design. NF and FC were responsible for, supervision of data collection, and interpretation of the data. AA, in collaboration with NF and FC, was responsible for data analyses. All authors were involved in manuscript drafting. All authors provided scientific input and edited and reviewed the manuscript content. All authors provided their final approval ad agree to be accountable for all aspects of the work, ensuring integrity and accuracy.

Funding: This research was funded from the primary author's start-up funds via the Island Medical Program of the University of British Columbia

Data Availability Statement: The datasets used and/or analyzed during the current study are available from the corresponding author on reasonable request.

Institutional Review Board Statement: This study was conducted in accordance with the Declaration of Helsinki. Ethical approval for this study was obtained from the Behavioural Ethics Board of the University of British Columbia (H15-03356), and written informed consent was obtained from all participants. The University of British Columbia's Behavioural Research Ethics Board follows the Canadian Tri-Counsel Policy Statement (TCPS): Ethical Conduct for Research Involving Humans. 
Informed Consent Statement: Informed consent was obtained from all subjects involved in the study.

Acknowledgments: The authors would like to thank the study participants for the generous gift of their time and thoughtful engagement. We would like to thank Jessica Gaiptman, Stephanie Poje, Rebecca Ferguson, Emily Friedrich, and Jennifer Suen for their invaluable contribution to participant recruitment and project management. We would also like to thank Rebecca Ferguson, Anika Brown, Sarah Ollerhead and Danielle Marwick for their contribution to participant interviewing.

Conflicts of Interest: The authors declare no conflict of interest.

\section{References}

[1] Kessler RC, Chiu WT, Demler O, Walters EE. Prevalence, Severity, and Comorbidity of 12-Month DSM-IV Disorders in the National Comorbidity Survey Replication. Arch Gen Psychiatry 2005;62:617-27. https://doi.org/10.1001/archpsyc.62.6.617.

[2] Kessler RC, Petukhova M, Sampson NA, Zaslavsky AM, Wittchen H-U. Twelve-month and lifetime prevalence and lifetime morbid risk of anxiety and mood disorders in the United States. Int J Methods Psychiatr Res 2012;21:169-84. https://doi.org/10.1002/mpr.1359.

[3] American Psychiatric Association. Diagnostic and statistical manual of mental disorders: DSM-5, 5th ed. Arlington, VA: American Psychiatric Publishing, Inc.; 2013. https://doi.org/10.1176/appi.books.9780890425596.

[4] American Psychiatric Association, editor. DSM-IV: Diagnostic and Statistical Manual of Mental Disorders. vol. 272.1994.

[5] Fawcett EJ, Fairbrother N, Cox ML, White IR, Fawcett JM. The Prevalence of Anxiety Disorders During Pregnancy and the Postpartum Period: A Multivariate Bayesian Meta-Analysis. J Clin Psychiatry 2019;80:1181. https://doi.org/10.4088/JCP.18r12527.

[6] Reck C, Struben K, Backenstrass M, Stefenelli U, Reinig K, Fuchs T, et al. Prevalence, onset and comorbidity of postpartum anxiety and depressive disorders. Acta Psychiatr Scand 2008;118:459-68. https://doi.org/10.1111/j.1600-0447.2008.01264.x.

[7] Woody CA, Ferrari AJ, Siskind DJ, Whiteford HA, Harris MG. A systematic review and meta-regression of the prevalence and incidence of perinatal depression. J Affect Disord 2017;219:86-92. https://doi.org/10.1016/j.jad.2017.05.003.

[8] Fifer SK, Mathias SD, Patrick DL, Mazonson PD, Lubeck DP, Buesching DP. Untreated Anxiety Among Adult Primary Care Patients in a Health Maintenance Organization. Arch Gen Psychiatry 1994;51:740-50. https://doi.org/10.1001/archpsyc.1994.03950090072010.

[9] Demers M. Frequent users of ambulatory health care in Quebec: the case of doctor-shoppers. CMAJ Can Med Assoc J 1995;153:37-42.

[10] Fournier L, Lesage AD, Toupin J, Cyr M. Telephone Surveys as an Alternative for Estimating Prevalence of Mental Disorders and Service Utilization: A Montreal Catchment Area Study. Can J Psychiatry 1997;42:737-43. https://doi.org/10.1177/070674379704200706.

[11] Horenstein A, Heimberg RG. Anxiety disorders and healthcare utilization: A systematic review. Clin Psychol Rev 2020;81:101894. https://doi.org/10.1016/j.cpr.2020.101894.

[12] McCusker J, Boulenger J-P, Boyer R, Bellavance F, Miller J-M. Use of Health Services for Anxiety Disorders: A Multisite Study in Quebec. Can J Psychiatry 1997;42:730-6. https://doi.org/10.1177/070674379704200705.

[13] Ohayon MM, Shapiro CM, Kennedy SH. Differentiating DSM-IV Anxiety and Depressive Disorders in the General Population: Comorbidity and Treatment Consequences. Can J Psychiatry 2000;45:166-72. https://doi.org/10.1177/070674370004500207.

[14] Ding X-X, Wu Y-L, Xu S-J, Zhu R-P, Jia X-M, Zhang S-F, et al. Maternal anxiety during pregnancy and adverse birth outcomes: A systematic review and meta-analysis of prospective cohort studies. J Affect Disord 2014;159:103-10. https://doi.org/10.1016/j.jad.2014.02.027.

[15] Matthey S. Anxiety and Stress During Pregnancy and the Postpartum Period. Oxf Handb Perinat Psychol 2016. https://doi.org/10.1093/oxfordhb/9780199778072.013.25.

[16] Mulder EJH, Robles de Medina PG, Huizink AC, Van den Bergh BRH, Buitelaar JK, Visser GHA. Prenatal maternal stress: effects on pregnancy and the (unborn) child. Early Hum Dev 2002;70:3-14. https://doi.org/10.1016/S0378-3782(02)00075-0.

[17] Schneider ML, Moore CF, Kraemer GW, Roberts AD, DeJesus OT. The impact of prenatal stress, fetal alcohol exposure, or both on development: perspectives from a primate model. Psychoneuroendocrinology 2002;27:285-98. https://doi.org/10.1016/S03064530(01)00050-6.

[18] Wadhwa PD, Glynn L, Hobel CJ, Garite TJ, Porto M, Chicz-DeMet A, et al. Behavioral perinatology: Biobehavioral processes in human fetal development. Regul Pept 2002;108:149-57. https://doi.org/10.1016/S0167-0115(02)00102-7.

[19] Adamson B, Letourneau N, Lebel C. Prenatal maternal anxiety and children's brain structure and function: A systematic review of neuroimaging studies. J Affect Disord 2018;241:117-26. https://doi.org/10.1016/j.jad.2018.08.029.

[20] Erickson NL, Gartstein MA, Dotson JAW. Review of Prenatal Maternal Mental Health and the Development of Infant Temperament. J Obstet Gynecol Neonatal Nurs 2017;46:588-600. https://doi.org/10.1016/j.jogn.2017.03.008. 
[21] Korja R, Nolvi S, Grant KA, McMahon C. The Relations Between Maternal Prenatal Anxiety or Stress and Child's Early Negative Reactivity or Self-Regulation: A Systematic Review. Child Psychiatry Hum Dev 2017;48:851-69. https://doi.org/10.1007/s10578017-0709-0.

[22] O'Connor TG, Heron J, Golding J, Glover V, Team the ASS. Maternal antenatal anxiety and behavioural/emotional problems in children: a test of a programming hypothesis. J Child Psychol Psychiatry 2003;44:1025-36. https://doi.org/10.1111/14697610.00187.

[23] O'Connor TG, Heron J, Glover V. Antenatal Anxiety Predicts Child Behavioral/Emotional Problems Independently of Postnatal Depression. J Am Acad Child Adolesc Psychiatry 2002;41:1470-7. https://doi.org/10.1097/00004583-200212000-00019.

[24] Rees S, Channon S, Waters CS. The impact of maternal prenatal and postnatal anxiety on children's emotional problems: a systematic review. Eur Child Adolesc Psychiatry 2019;28:257-80. https://doi.org/10.1007/s00787-018-1173-5.

[25] Grigoriadis S, Graves L, Peer M, Mamisashvili L, Tomlinson G, Vigod SN, et al. A systematic review and meta-analysis of the effects of antenatal anxiety on postpartum outcomes. Arch Womens Ment Health 2019;22:543-56. https://doi.org/10.1007/s00737-018-0930-2.

[26] Matthey S, Barnett B, Howie P, Kavanagh DJ. Diagnosing postpartum depression in mothers and fathers: whatever happened to anxiety? J Affect Disord 2003;74:139-47. https://doi.org/10.1016/S0165-0327(02)00012-5.

[27] Robertson E, Grace S, Wallington T, Stewart DE. Antenatal risk factors for postpartum depression: a synthesis of recent literature. Gen Hosp Psychiatry 2004;26:289-95. https://doi.org/10.1016/j.genhosppsych.2004.02.006.

[28] Sutter-Dallay AL, Giaconne-Marcesche V, Glatigny-Dallay E, Verdoux H. Women with anxiety disorders during pregnancy are at increased risk of intense postnatal depressive symptoms: a prospective survey of the MATQUID cohort. Eur Psychiatry 2004;19:459-63. https://doi.org/10.1016/j.eurpsy.2004.09.025.

[29] Bánhidy F, Ács N, Puhó E, Czeizel AE. Association between maternal panic disorders and pregnancy complications and delivery outcomes. Eur J Obstet Gynecol Reprod Biol 2006;124:47-52. https://doi.org/10.1016/j.ejogrb.2005.04.013.

[30] Chen Y-H, Lin H-C, Lee H-C. Pregnancy outcomes among women with panic disorder - Do panic attacks during pregnancy matter? J Affect Disord 2010;120:258-62. https://doi.org/10.1016/j.jad.2009.04.025.

[31] Lilliecreutz C, Sydsjö G, Josefsson A. Obstetric and perinatal outcomes among women with blood-and injection phobia during pregnancy. J Affect Disord 2011;129:289-95. https://doi.org/10.1016/j.jad.2010.08.013.

[32] Seng JS, Oakley DJ, Sampselle CM, Killion C, Graham-Bermann S, Liberzon I. Posttraumatic stress disorder and pregnancy complications. Obstet Gynecol 2001;97:17-22. https://doi.org/10.1016/S0029-7844(00)01097-8.

[33] Yonkers KA, Blackwell KA, Glover J, Forray A. Antidepressant Use in Pregnant and Postpartum Women. Annu Rev Clin Psychol 2014;10:369-92. https://doi.org/10.1146/annurev-clinpsy-032813-153626.

[34] Challacombe FL, Salkovskis PM, Woolgar M, Wilkinson EL, Read J, Acheson R. Parenting and mother-infant interactions in the context of maternal postpartum obsessive-compulsive disorder: Effects of obsessional symptoms and mood. Infant Behav Dev 2016;44:11-20. https://doi.org/10.1016/j.infbeh.2016.04.003.

[35] Castelli RD, de Ávila Quevedo L, da Cunha Coelho FM, Lopez MA, da Silva RA, Böhm DM, et al. Cognitive and language performance in children is associated with maternal social anxiety disorder: A study of young mothers in southern Brazil. Early Hum Dev 2015;91:707-11. https://doi.org/10.1016/j.earlhumdev.2015.10.002.

[36] Martini J, Knappe S, Beesdo-Baum K, Lieb R, Wittchen H-U. Anxiety disorders before birth and self-perceived distress during pregnancy: Associations with maternal depression and obstetric, neonatal and early childhood outcomes. Early Hum Dev 2010;86:305-10. https://doi.org/10.1016/j.earlhumdev.2010.04.004.

[37] O'Connell MA, Leahy-Warren P, Khashan AS, Kenny LC, O'Neill SM. Worldwide prevalence of tocophobia in pregnant women: systematic review and meta-analysis. Acta Obstet Gynecol Scand 2017;96:907-20. https://doi.org/10.1111/aogs.13138.

[38] Clark LA, Cuthbert B, Lewis-Fernández R, Narrow WE, Reed GM. Three Approaches to Understanding and Classifying Mental Disorder: ICD-11, DSM-5, and the National Institute of Mental Health's Research Domain Criteria (RDoC). Psychol Sci Public Interest 2017;18:72-145. https://doi.org/10.1177/1529100617727266.

[39] Eaton WW, Neufeld K, Chen L-S, Cai G. A Comparison of Self-report and Clinical Diagnostic Interviews for Depression: Diagnostic Interview Schedule and Schedules for Clinical Assessment in Neuropsychiatry in the Baltimore Epidemiologic Catchment Area Follow-up. Arch Gen Psychiatry 2000;57:217-22. https://doi.org/10.1001/archpsyc.57.3.217.

[40] Thombs BD, Kwakkenbos L, Levis AW, Benedetti A. Addressing overestimation of the prevalence of depression based on selfreport screening questionnaires. CMAJ 2018;190:E44-9. https://doi.org/10.1503/cmaj.170691.

[41] Räisänen S, Lehto S, Nielsen H, Gissler M, Kramer M, Heinonen S. Fear of childbirth in nulliparous and multiparous women: a population-based analysis of all singleton births in Finland in 1997-2010. BJOG Int J Obstet Gynaecol 2014;121:965-70. https://doi.org/10.1111/1471-0528.12599.

[42] Calderani E, Giardinelli L, Scannerini S, Arcabasso S, Compagno E, Petraglia F, et al. Tocophobia in the DSM-5 era: Outcomes of a new cut-off analysis of the Wijma delivery expectancy/experience questionnaire based on clinical presentation. J Psychosom Res 2019;116:37-43. https://doi.org/10.1016/j.jpsychores.2018.11.012.

[43] Hofberg K, Brockington I. Tokophobia: An unreasoning dread of childbirth: A series of 26 cases. Br J Psychiatry 2000;176:83-5. https://doi.org/10.1192/bjp.176.1.83. 
[44] Sydsjö G, Bladh M, Lilliecreutz C, Persson A-M, Vyöni H, Josefsson A. Obstetric outcomes for nulliparous women who received routine individualized treatment for severe fear of childbirth - a retrospective case control study. BMC Pregnancy Childbirth 2014;14:126. https://doi.org/10.1186/1471-2393-14-126.

[45] Zar M, Wijma K, Wijma B. Relations between anxiety disorders and fear of childbirth during late pregnancy. Clin Psychol Psychother 2002;9:122-30. https://doi.org/10.1002/cpp.305.

[46] Challacombe FL, Nath S, Trevillion K, Pawlby S, Howard LM. Fear of childbirth during pregnancy: associations with observed mother-infant interactions and perceived bonding. Arch Womens Ment Health 2021;24:483-92. https://doi.org/10.1007/s00737020-01098-w.

[47] Lukasse M, Schei B, Ryding EL. Prevalence and associated factors of fear of childbirth in six European countries. Sex Reprod Healthc 2014;5:99-106. https://doi.org/10.1016/j.srhc.2014.06.007.

[48] Nilsson C, Hessman E, Sjöblom H, Dencker A, Jangsten E, Mollberg M, et al. Definitions, measurements and prevalence of fear of childbirth: a systematic review. BMC Pregnancy Childbirth 2018;18:28. https://doi.org/10.1186/s12884-018-1659-7.

[49] O'Connell MA, Leahy-Warren P, Kenny LC, O'Neill SM, Khashan AS. The prevalence and risk factors of fear of childbirth among pregnant women: A cross-sectional study in Ireland. Acta Obstet Gynecol Scand 2019;98:1014-23. https://doi.org/10.1111/aogs.13599.

[50] Hofberg K, Ward MR. Fear of pregnancy and childbirth. Postgrad Med J 2003;79:505-10. https://doi.org/10.1136/pmj.79.935.505.

[51] Möller L, Josefsson A, Lilliecreutz C, Gunnervik C, Bladh M, Sydsjö G. Reproduction, fear of childbirth and obstetric outcomes in women treated for fear of childbirth in their first pregnancy: A historical cohort. Acta Obstet Gynecol Scand 2019;98:374-81. https://doi.org/10.1111/aogs.13503.

[52] Zar M, Wijma K, Wijma B. Pre- and Postpartum Fear of Childbirth in Nulliparous and Parous Women. Scand J Behav Ther 2001;30:75-84. https://doi.org/10.1080/02845710121310.

[53] Adams S, Eberhard-Gran M, Eskild A. Fear of childbirth and duration of labour: a study of 2206 women with intended vaginal delivery. BJOG Int J Obstet Gynaecol 2012;119:1238-46. https://doi.org/10.1111/j.1471-0528.2012.03433.x.

[54] Ryding EL, Lukasse M, Parys A-SV, Wangel A-M, Karro H, Kristjansdottir H, et al. Fear of Childbirth and Risk of Cesarean Delivery: A Cohort Study in Six European Countries. Birth 2015;42:48-55. https://doi.org/10.1111/birt.12147.

[55] Takegata M, Haruna M, Matsuzaki M, Shiraishi M, Okano T, Severinsson E. Does antenatal fear of childbirth predict postnatal fear of childbirth? - A study of Japanese women 2015. https://doi.org/10.4236/ojn.2015.52017.

[56] Fuglenes D, Aas E, Botten G, Øian P, Kristiansen IS. Why do some pregnant women prefer cesarean? The influence of parity, delivery experiences, and fear. Am J Obstet Gynecol 2011;205:45.e1-45.e9. https://doi.org/10.1016/j.ajog.2011.03.043.

[57] Haines HM, Rubertsson C, Pallant JF, Hildingsson I. The influence of women's fear, attitudes and beliefs of childbirth on mode and experience of birth. BMC Pregnancy Childbirth 2012;12:55. https://doi.org/10.1186/1471-2393-12-55.

[58] Handelzalts JE, Fisher S, Lurie S, Shalev A, Golan A, Sadan O. Personality, fear of childbirth and cesarean delivery on demand. Acta Obstet Gynecol Scand 2012;91:16-21. https://doi.org/10.1111/j.1600-0412.2011.01287.x.

[59] Nieminen K, Stephansson O, Ryding EL. Women's fear of childbirth and preference for cesarean section - a cross-sectional study at various stages of pregnancy in Sweden. Acta Obstet Gynecol Scand 2009;88:807-13. https://doi.org/10.1080/00016340902998436.

[60] Wiklund I, Edman G, Andolf E. Cesarean section on maternal request: reasons for the request, self-estimated health, expectations, experience of birth and signs of depression among first-time mothers. Acta Obstet Gynecol Scand 2007;86:451-6. https://doi.org/10.1080/00016340701217913.

[61] Saisto T, Salmela-Aro K, Nurmi J-E, Halmesmäki E. Psychosocial characteristics of women and their partners fearing vaginal childbirth. Br J Obstet Gynaecol 2001;108:492-8. https://doi.org/10.1016/S0306-5456(00)00122-4.

[62] Salomonsson B, Gullberg MT, Alehagen S, Wijma K. Self-efficacy beliefs and fear of childbirth in nulliparous women. J Psychosom Obstet Gynecol 2013;34:116-21. https://doi.org/10.3109/0167482X.2013.824418.

[63] Stoll K, Hauck Y, Downe S, Edmonds J, Gross MM, Malott A, et al. Cross-cultural development and psychometric evaluation of a measure to assess fear of childbirth prior to pregnancy. Sex Reprod Healthc 2016;8:49-54. https://doi.org/10.1016/j.srhc.2016.02.004.

[64] Otley H. Fear of childbirth: Understanding the causes, impact and treatment. Br J Midwifery 2011;19:215-20. https://doi.org/10.12968/bjom.2011.19.4.215.

[65] Waldenström U, Hildingsson I, Ryding E. Antenatal fear of childbirth and its association with subsequent caesarean section and experience of childbirth. BJOG Int J Obstet Gynaecol 2006;113:638-46. https://doi.org/10.1111/j.1471-0528.2006.00950.x.

[66] Størksen HT, Garthus-Niegel S, Vangen S, Eberhard-Gran M. The impact of previous birth experiences on maternal fear of childbirth. Acta Obstet Gynecol Scand 2013;92:318-24. https://doi.org/10.1111/aogs.12072.

[67] Alipour Z, Lamyian M, Hajizadeh E. Anxiety and fear of childbirth as predictors of postnatal depression in nulliparous women. Women Birth 2012;25:e37-43. https://doi.org/10.1016/j.wombi.2011.09.002.

[68] Ayers S. Fear of childbirth, postnatal post-traumatic stress disorder and midwifery care. Midwifery 2014;30:145-8. https://doi.org/10.1016/j.midw.2013.12.001.

[69] Nath S, Busuulwa P, Ryan EG, Challacombe FL, Howard LM. The characteristics and prevalence of phobias in pregnancy. Midwifery 2020;82:102590. https://doi.org/10.1016/j.midw.2019.102590. 
[70] Storksen HT, Eberhard-Gran M, Garthus-Niegel S, Eskild A. Fear of childbirth; the relation to anxiety and depression. Acta Obstet Gynecol Scand 2012;91:237-42. https://doi.org/10.1111/j.1600-0412.2011.01323.x.

[71] Rouhe H, Salmela-Aro K, Halmesmäki E, Saisto T. Fear of childbirth according to parity, gestational age, and obstetric history. BJOG Int J Obstet Gynaecol 2009;116:67-73. https://doi.org/10.1111/j.1471-0528.2008.02002.x.

[72] Fairbrother N, Thordarson DS, Stoll K. Fine tuning fear of childbirth: the relationship between Childbirth Fear Questionnaire subscales and demographic and reproductive variables. J Reprod Infant Psychol 2018;36:15-29. https://doi.org/10.1080/02646838.2017.1396300.

[73] Jokić-Begić N, Žigić L, Nakić Radoš S. Anxiety and anxiety sensitivity as predictors of fear of childbirth: different patterns for nulliparous and parous women. J Psychosom Obstet Gynecol 2014;35:22-8. https://doi.org/10.3109/0167482X.2013.866647.

[74] Poikkeus P, Saisto T, Unkila-Kallio L, Punamaki RL, Repokari L, Vilska S, et al. Fear of Childbirth and Pregnancy-Related Anxiety in Women Conceiving With Assisted Reproduction. Obstet Gynecol 2006;108:70-6. https://doi.org/10.1097/01.AOG.0000222902.37120.2f.

[75] Gao L, Liu XJ, Fu BL, Xie W. Predictors of childbirth fear among pregnant Chinese women: A cross-sectional questionnaire survey. Midwifery 2015;31:865-70. https://doi.org/10.1016/j.midw.2015.05.003.

[76] Laursen M, Hedegaard M, Johansen C. Fear of childbirth: predictors and temporal changes among nulliparous women in the Danish National Birth Cohort. BJOG Int J Obstet Gynaecol 2008;115:354-60. https://doi.org/10.1111/j.1471-0528.2007.01583.x.

[77] Nerum H, Halvorsen L, Straume B, Sørlie T, Øian P. Different labour outcomes in primiparous women that have been subjected to childhood sexual abuse or rape in adulthood: a case-control study in a clinical cohort. BJOG Int J Obstet Gynaecol 2013;120:487-95. https://doi.org/10.1111/1471-0528.12053.

[78] Gourounti K, Kouklaki E, Lykeridou K. Validation of the Childbirth Attitudes Questionnaire in Greek and psychosocial characteristics of pregnant women with fear of childbirth. Women Birth 2015;28:e44-51. https://doi.org/10.1016/j.wombi.2015.02.004.

[79] Lowe NK. Self-efficacy for labor and childbirth fears in nulliparous pregnant women. J Psychosom Obstet Gynecol 2000;21:219_ 24. https://doi.org/10.3109/01674820009085591.

[80] Heimstad R, Dahloe R, Laache I, Skogvoll E, Schei B. Fear of childbirth and history of abuse: implications for pregnancy and delivery. Acta Obstet Gynecol Scand 2006;85:435-40. https://doi.org/10.1080/00016340500432507.

[81] Hall WA, Hauck YL, Carty EM, Hutton EK, Fenwick J, Stoll K. Childbirth Fear, Anxiety, Fatigue, and Sleep Deprivation in Pregnant Women. J Obstet Gynecol Neonatal Nurs 2009;38:567-76. https://doi.org/10.1111/j.1552-6909.2009.01054.x.

[82] Fairbrother N, Collardeau F, Albert A, Thordarson DS, Stoll K. Screening for Perinatal Anxiety using the Childbirth Fear Questionnaire: A New Measure of Fear of Childbirth. Rev 2022. https://doi.org/10.21203/rs.3.rs-568026/v1.

[83] Areskog B, Kjessler B, Uddenberg N. Identification of Women with Significant Fear of Childbirth during Late Pregnancy. Gynecol Obstet Invest 1982;13:98-107. https://doi.org/10.1159/000299490.

[84] Elvander C, Cnattingius S, Kjerulff KH. Birth Experience in Women with Low, Intermediate or High Levels of Fear: Findings from the First Baby Study. Birth 2013;40:289-96. https://doi.org/10.1111/birt.12065.

[85] Eriksson C, Westman G, Hamberg K. Experiential factors associated with childbirth-related fear in Swedish women and men: A population based study. J Psychosom Obstet Gynecol 2005;26:63-72. https://doi.org/10.1080/01674820400023275.

[86] Hildingsson I, Nilsson C, Karlström A, Lundgren I. A Longitudinal Survey of Childbirth-Related Fear and Associated Factors. J Obstet Gynecol Neonatal Nurs 2011;40:532-43. https://doi.org/10.1111/j.1552-6909.2011.01274.x.

[87] Melender H-L. Experiences of Fears Associated with Pregnancy and Childbirth: A Study of 329 Pregnant Women. Birth 2002;29:101-11. https://doi.org/10.1046/j.1523-536X.2002.00170.x.

[88] Prelog PR, Makovec MR, Šimic MV, Sršen TP, Perat M. Individual and Contextual Factors of Nulliparas' Levels of Depression, Anxiety and Fear of Childbirth in the Last Trimester of Pregnancy: Intimate Partner Attachment a Key Factor? Slov J Public Health 2019;58:112-9. https://doi.org/10.2478/sjph-2019-0015.

[89] Saxbe D, Horton KT, Tsai AB. The Birth Experiences Questionnaire: A brief measure assessing psychosocial dimensions of childbirth. J Fam Psychol 2018;32:262-8. https://doi.org/10.1037/fam0000365.

[90] Wijma K, Wijma B, Zar M. Psychometric aspects of the W-DEQ; a new questionnaire for the measurement of fear of childbirth. J Psychosom Obstet Gynecol 1998;19:84-97. https://doi.org/10.3109/01674829809048501.

[91] Wootton BM, Davis E, Moses K, Moody A, Maguire P. The development and initial validation of the Tokophobia Severity Scale. Clin Psychol 2020;24:267-75. https://doi.org/10.1111/cp.12220.

[92] Slade P, Pais T, Fairlie F, Simpson A, Sheen K. The development of the Slade-Pais Expectations of Childbirth Scale (SPECS). J Reprod Infant Psychol 2016;34:495-510. https://doi.org/10.1080/02646838.2016.1209300.

[93] Redshaw M, Martin C, Rowe R, Hockley C. The Oxford Worries about Labour Scale: Women's experience and measurement characteristics of a measure of maternal concern about labour and birth. Psychol Health Med 2009;14:354-66. https://doi.org/10.1080/13548500802707159.

[94] Austin MP, Highet N, Expert Working Group. Mental health care in the perinatal period: Australian clinical practice guideline 2017.

[95] Hart KJ, Flynn HA. Screening, assessment, and diagnosis of mood and anxiety disorders during pregnancy and the postpartum period. Oxf. Handb. Perinat. Psychol., New York, NY, US: Oxford University Press; 2016, p. 319-40.

[96] Stoll K, Fairbrother N, Thordarson DS. Childbirth Fear: Relation to Birth and Care Provider Preferences. J Midwifery Womens Health 2018;63:58-67. https://doi.org/10.1111/jmwh.12675. 
[97] Fairbrother N, Corbyn B, Thordarson DS, Ma A, Surm D. Screening for Perinatal Anxiety Disorders: Room to grow. J Affect Disord 2019;250:363-70. https://doi.org/10.1016/j.jad.2019.03.052.

[98] Sackett DL, Rosenberg WMC, Gray JAM, Haynes RB, Richardson WS. Evidence based medicine: what it is and what it isn't. BMJ 1996;312:71-2. https://doi.org/10.1136/bmj.312.7023.71.

[99] Johnson R, Slade P. Does fear of childbirth during pregnancy predict emergency caesarean section? BJOG Int J Obstet Gynaecol 2002;109:1213-21. https://doi.org/10.1016/S1470-0328(02)01951-1.

[100] Garthus-Niegel S, Størksen HT, Torgersen L, Von Soest T, Eberhard-Gran M. The Wijma Delivery Expectancy/Experience Questionnaire - a factor analytic study. J Psychosom Obstet Gynecol 2011;32:160-3. https://doi.org/10.3109/0167482X.2011.573110.

[101] McCabe RE, Milosevic I, Rowa K, Shnaider P, Pawluk EJ, Antony MM. Diagnostic Assessment Research Tool (DART) 2017.

[102] Schneider LH, Pawluk EJ, Milosevic I, Shnaider P, Rowa K, Antony MM, et al. The Diagnostic Assessment Research Tool in action: A preliminary evaluation of a semistructured diagnostic interview for DSM-5 disorders. Psychol Assess 2021:No Pagination Specified-No Pagination Specified. https://doi.org/10.1037/pas0001059.

[103] R Core Team. R: A language and environment for statistical computing. Foundation for Statistical Computing, Vienna, Austria.; 2021.

[104] IBM Corp. IBM SPSS Statistics for Windows, Version 24.0. Armonk, NY: IBM Corp; 2016.

[105] Bujang MA, Adnan TH. Requirements for Minimum Sample Size for Sensitivity and Specificity Analysis. J Clin Diagn Res JCDR 2016;10:YE01-6. https://doi.org/10.7860/JCDR/2016/18129.8744.

[106] Holtman GA, Berger MY, Burger H, Deeks JJ, Donner-Banzhoff N, Fanshawe TR, et al. Development of practical recommendations for diagnostic accuracy studies in low-prevalence situations. J Clin Epidemiol 2019;114:38-48. https://doi.org/10.1016/j.jclinepi.2019.05.018.

[107] Thiele C, Hirschfeld G. cutpointr: Improved Estimation and Validation of Optimal Cutpoints in R. ArXiv200209209 Stat 2020. 